EXTENDED REPORT

\title{
Is early surgery for congenital cataract a risk factor for glaucoma?
}

\author{
M Vishwanath, R Cheong-Leen, D Taylor, I Russell-Eggitt, J Rahi
}

Br J Ophthalmol 2004;88:905-910. doi: 10.1136/bjo.2003.040378

See end of article for authors' affiliations

....................

Correspondence to: Dr R Cheong-Leen, Institute of Child Health, London, UK; r.cl@btinternet.com

Accepted for publication 23 February 2004

\begin{abstract}
Aims: To estimate the risk of aphakic glaucoma after lensectomy for congenital cataract and its association with surgery within the first month of life.

Method: A retrospective case notes review was conducted of all patients who had lensectomy for congenital cataract during their first year of life at Great Ormond Street Hospital between 1994 and 1997. Patients with pre-existing glaucoma, anterior segment dysgenesis, and Lowe syndrome were excluded. The risk of aphakic glaucoma after surgery was estimated using Kaplan-Meier survival analysis.

Results: 80 patients, undergoing 128 lensectomies were eligible. Of these, six patients (nine eyes) were lost to follow up. Based on eye count, the risk of glaucoma by 5 years after lensectomy was $15.6 \% 195 \% \mathrm{Cl}$ 10.2 to 23.4). Based on patient count, the 5 year risk of glaucoma in at least one eye following bilateral surgery was $25.1 \%(95 \% \mathrm{Cl} 15.1$ to 40.0$)$. The incidence of glaucoma remained at a constant level for the first 5 years after surgery. After early bilateral lensectomy, within the first month of life, the 5 year risk of glaucoma in at least one eye was $50 \%(95 \% \mathrm{Cl} 27.8$ to 77.1$)$ compared to $14.9 \%$ (95\% Cl 6.5 to 32.1$)$ with surgery performed later (log rank test, $p=0.012$ ). There was no significant difference (KolmogorovSmirnov test: unilateral lensectomy $p=0.587$, bilateral lensectomy $p=0.369$ ) in 5 year visual outcomes between eyes operated before and after 1 month of age.

Conclusion: Bilateral lensectomy during the first month of life is associated with a higher risk of subsequent glaucoma than with surgery performed later. The reason for this is unclear but it may be prudent, in bilateral cases, to consider delaying surgery until the infant is 4 weeks old. As the incidence of glaucoma is similar for each year after surgery, long term glaucoma surveillance is mandatory.
\end{abstract}

A phakic glaucoma is an established complication following lensectomy for congenital cataract. ${ }^{1-5}$ It presents as early angle closure glaucoma caused by vitreous pupillary block, inflammatory peripheral anterior synechiae, $^{6-8}$ or proliferating retained lens matter. More commonly, it presents as open angle glaucoma up to years after surgery. ${ }^{34-11}$ The risk of aphakic glaucoma may be higher with infants operated during the first year of life. ${ }^{6}{ }^{12} 13$

As glaucoma in children can be difficult to manage, parents should be counselled about its likelihood and consequences. The reported prevalence of postoperative glaucoma varies between $6 \%$ and $26 \%$ of eyes (15\% to $45 \%$ of patients) among children operated before, as well as after, 1 year of age. ${ }^{12}{ }^{14-19}$ With widespread screening of neonates for congenital cataract, affected infants are increasingly referred by 3 months of age. ${ }^{20}$ Thus, it is important to reexamine the risk of postoperative glaucoma specifically within this subgroup of infants.

The timing of congenital cataract surgery can have a major impact on long term prognosis. Surgery after 6 weeks of age may deprive the neonatal visual system of vital stimuli during the critical period. ${ }^{21}$ Surgery before $1-2$ weeks of age has been reported to be associated with a higher risk of glaucoma. ${ }^{14}{ }^{15} 22$ However, in a recent study, Watts ${ }^{23}$ et al suggested that the first 2 weeks of life was "the most favourable time" to perform lensectomy, with significantly fewer cases of subsequent aphakic glaucoma.

\section{METHODS}

\section{Subjects}

We conducted a retrospective case notes review of all infants who underwent lensectomy at Great Ormond Street Hospital (GOSH) for congenital cataract at age less than 1 year between January 1994 and December 1997. Where necessary, we asked ophthalmologists working at regional eye units to complete standard questionnaires to provide information on clinical outcomes of the patients managed postoperatively at their hospitals.

Eyes with persistent hyperplastic primary vitreous (PHPV) fetal vasculature were included in the study whereas patients with other ocular malformations, pre-existing glaucoma, anterior segment dysgenesis, Lowe syndrome, congenital rubella syndrome, or surgery performed outside GOSH were excluded. We did not exclude infants with PHPV as our preliminary analysis showed that eyes with PHPV in our series had similar level of risk of glaucoma $(0 \% 95 \%$ CI 0 to 28.3 ) as eyes with isolated congenital cataract ( $16.8 \% 95 \%$ CI 11.1 to 25.1$)$.

\section{Surgical techniques}

In all cases, lensectomy was performed through a limbal incision followed by a shallow anterior vitrectomy. None of the infants received intraocular lens implant. Seventy four lensectomies were performed by the two consultant coauthors (DT, IRE); 54 cases by senior fellows under consultant supervision.

Postoperatively, all patients received medication according to the GOSH eye unit protocol: subconjunctival cefuroxime and Betnesol immediately after operation, followed by Maxitrol drops hourly the next day and 2 hourly the day after, tapering over a 6 week period. We also used cyclopentolate $1 \%$ ( $0.5 \%$ for those less than 4 months old $)$ twice a day and Maxitrol ointment at night during the first postoperative week. Contact lens fitting was usually 1 week after lensectomy.

\section{Diagnosis of aphakic glaucoma}

The diagnosis of aphakic glaucoma is not always straightforward in this age group. We designated cases as glaucomatous 
based on the consultant's decision to initiate permanent medical treatment or glaucoma surgery (including anterior vitrectomy). Glaucomatous eyes that required anterior vitrectomy additional to that performed as part of the original operation were classified as having angle closure aphakic glaucoma. Glaucomatous eyes managed without vitrectomy were classified as open angle aphakic glaucoma. Gonioscopy is the gold standard test for distinguishing between open and closed angle glaucoma. However, gonioscopy findings were recorded in operation notes of only 21 eyes out of the total 128 eyes.

\section{Analysis}

The risk of glaucoma was estimated using Kaplan-Meier survival analysis. During preliminary analysis, we divided the time at surgery into twelve 30 day periods. There was a higher rate of glaucoma associated with operation performed during the first month of life (as shown in fig 2). The log rank test was used to compare the risk of glaucoma in early (before 1 month) versus late lensectomy. Because of the multiple statistical testing in this study, we adjusted the type 1 error using Bonferroni correction (type 1 error $=0.0047$, number of statistical tests $=11$ ).

\section{RESULTS}

\section{The cohort}

Of the 86 consecutive patients, six were excluded because of pre-existing glaucoma or Lowe syndrome. Thirty of 80 infants underwent unilateral lensectomy, 19 of them had unilateral congenital cataract, nine had unilateral PHPV, and the remaining two had asymmetrical bilateral cataract not needing lensectomy to the second eye. Fifty of 80 patients had bilateral lensectomy, of which two had their first operation performed outside GOSH. The data from 128 lensectomies on 80 infants were included in this study.

\section{Year cumulative incidence of glaucoma}

By 5 years after surgery, 19 eyes ( 13 patients) had developed glaucoma and nine of them (seven patients) required surgical intervention. six patients (nine eyes) were lost to follow up within 5 years. Based on eye count, the 5 year risk of glaucoma was $15.6 \%$ (95\% CI 10.2 to 23.4 ). There was no significant difference in glaucoma rate between the two consultant surgeons (log rank test $\mathrm{p}=0.513$ ).

We analysed the risk of glaucoma after unilateral and after bilateral lensectomy separately. Among the 30 infants with unilateral surgery, one (table 1 patient 11) developed open angle glaucoma requiring permanent medication and another (patient 1) developed early angle closure glaucoma, which responded to anterior vitrectomy with pupilloplasty without further need for ocular antihypertensive medication. Among infants who underwent bilateral lensectomy, the 5 year risk of glaucoma in at least one eye was $25.1 \%$ (95\% CI 15.1 to 40.0).

\section{Presentation and incidence of glaucoma}

The earliest diagnosis of glaucoma in our series was 12 days after surgery (table 1 patient 1 ) and the latest (patient 13 left eye) in the middle of the fifth year. The apparent higher incidence of glaucoma during year 1 and year 4 was not statistically significant $\left(\chi_{4}^{2} \mathrm{p}=0.33\right)$. The average yearly incidence of glaucoma during the first 5 years was 3.3\% (95\% CI 2.1 to 5.2) of all eyes and 5.6\% (95\% CI 3.2 to 9.7) of all patients who underwent bilateral lensectomy.

Seven eyes (5.5\%, CI 2.7 to 11.2 ) from six patients (patients 1-6) presented with angle closure glaucoma within the first year. Six of these eyes presented initially with corneal oedema. Two eyes (patients 1 and 3) responded to anterior vitrectomy and did not require ocular hypotensive medication afterwards. Of the remaining five eyes from four patients on permanent medication (3.9\%, CI 1.7 to 9.2 ), four eyes (three patients) required multiple surgery for glaucoma control.

Table 1 The clinical outcomes of glaucomatous eyes in the series

\begin{tabular}{|c|c|c|c|c|c|c|c|}
\hline Patient & Eye & $\begin{array}{l}\text { Timing of } \\
\text { surgery (days) }\end{array}$ & $\begin{array}{l}\text { Glaucoma } \\
\text { onset (days) }\end{array}$ & Presenting sign & $\begin{array}{l}\text { 1st line of } \\
\text { treatment }\end{array}$ & $\begin{array}{l}\text { 2nd line of treatment and } 5 \text { year } \\
\text { visual outcomes (logMAR) }\end{array}$ & Other features \\
\hline $1 \dagger$ & right & 79 & 12 & Corneal oedema, OHT & Vitrectomy & $\begin{array}{l}\text { Medication not required after } \\
\text { vitrectomy, vision } 0.8\end{array}$ & \\
\hline 2 & right & $14^{*}$ & 37 & Corneal oedema, OHT & $\begin{array}{l}\text { Vitrectomy } \\
\text { Medication }\end{array}$ & $\begin{array}{l}\text { Trabeculotomy, cyclodiode } \\
\times 2 \text {, Vision NPL }\end{array}$ & $c / d$ ratio 0.7 \\
\hline 2 & left & $16^{*}$ & 40 & Corneal oedema, OHT & $\begin{array}{l}\text { Vitrectomy } \\
\text { Medication }\end{array}$ & Cyclodiode $\times 2$, vision PL & PAS, c/d ratio 0.55 \\
\hline 3 & right & 42 & 46 & $\mathrm{OHT}$ & Vitrectomy & $\begin{array}{l}\text { Weaned off medication after } \\
\text { vitrectomy within first year, } \\
\text { vision missing }\end{array}$ & PAS \\
\hline 4 & left & $10^{*}$ & 70 & Corneal oedema, OHT & $\begin{array}{l}\text { Vitrectomy } \\
\text { Medication }\end{array}$ & $\begin{array}{l}\text { Goniotomy, trabeculectomy, } \\
\text { cyclodiode } \times 2 \text {, Ahmed tube, } \\
\text { vision } \mathrm{HM}\end{array}$ & c/d ratio 1.0 \\
\hline 5 & right & $27^{*}$ & 85 & Corneal oedema, OHT & $\begin{array}{l}\text { Vitrectomy } \\
\text { Medication }\end{array}$ & Trabeculectomy, vision 0.9 & \\
\hline 6 & left & 79 & 334 & Corneal oedema, OHT & Medication & Vitrectomy, vision 0.8 & \\
\hline 7 & right & 95 & 490 & Corneal oedema, OHT & Medication & Cyclodiode, vision 0.5 & \\
\hline 8 & right & 39 & 695 & Corneal oedema, OHT & Medication & Cyclodiode, vision 1.5 & Myopic shift, PAS \\
\hline 9 & left & $26^{*}$ & 800 & OHT & Medication & Vision 0.1 & PAS \\
\hline 9 & right & $14^{*}$ & 812 & OHT & Medication & Vision 0.3 & \\
\hline 10 & left & $15^{*}$ & 1013 & Not available & Not available & $\begin{array}{l}\text { Trabeculectomy, cyclodiode, } \\
\text { vision } 0.8\end{array}$ & Not available \\
\hline $11 \dagger$ & left & $20^{*}$ & 1111 & OHT & Medication & Vision 0.5 & $c / d$ ratio 0.5 \\
\hline 12 & right & $11^{*}$ & 1185 & OHT & Medication & Cyclodiode, vision 0.2 & \\
\hline 8 & left & 88 & 1213 & Not available & Not available & Cyclodiode, vision 0.3 & Not available \\
\hline 13 & right & 79 & 1305 & OHT & Medication & Vision 0.6 & \\
\hline 14 & left & $29^{*}$ & 1370 & $\mathrm{OHT}$ & Medication & Vision 0.2 & PAS, c/d ratio 0.55 \\
\hline 15 & left & 108 & 1382 & OHT & Medication & Vision 0.8 & $\mathrm{c} / \mathrm{d}$ ratio 0.5 \\
\hline 15 & Right & 95 & 1416 & OHT & Medication & Vision 1.0 & PAS \\
\hline 12 & Left & $13^{*}$ & 1644 & Not available & Not available & Vision 0.8 & Not available \\
\hline 13 & Left & 71 & 1735 & OHT & Medication & Vision 0.7 & \\
\hline
\end{tabular}


A further 14 eyes from nine patients (patients 7-15) presented with open angle glaucoma after the first year. We were unable to ascertain the clinical presentation of three patients (three eyes), who were monitored outside GOSH. The remaining 11 eyes all had asymptomatic ocular hypertension $(>22 \mathrm{~mm} \mathrm{Hg})$ found either in clinic or during examination under anaesthetic. In addition, corneal haze (patients 7 and 8) was noted in two eyes, peripheral synechiae in another four eyes, and disc changes in another three eyes. Five eyes (four patients) in this subgroup required additional surgery for glaucoma control.

\section{The timing of surgery}

The timing of lensectomy ranges from age 5 days to age 352 days with a median value of 58.5 days. Figures $1-3$ and tables 2-4 show that eyes from bilateral cases operated during the first month of life had a significantly higher risk ( $\log$ rank test $\mathrm{p}=0.001$ ) of glaucoma within 5 years compared to eyes operated later. There was no significant difference ( $\log$ rank test $\mathrm{p}=0.67$ ) between eyes operated during the first half and during the second half of the first month. The yearly variation of the incidence of glaucoma within the early surgery subgroup (before 1 month of age) was not statistically significant $\left(\chi_{4}{ }^{2}\right.$ test: based on eye count $\mathrm{p}=0.15 \mathrm{l}$, based on patients developing glaucoma in at least one eye after bilateral lensectomy $\mathrm{p}=0.149$ ).

In this series, three eyes (table 1 , patients 2 and 4) sustained irreversible severe visual loss (hand movement or worse) as a result of aggressive angle closure glaucoma: all three were operated before 1 month of age. However, the small size of our sample precluded examination of the association between the timing of surgery and the risk of severe visual loss among glaucomatous eyes.

\section{Vision}

There was no significant difference (Kolmogorov-Smirnov test: unilateral lensectomy $\mathrm{p}=0.587$, bilateral lensectomy $\mathrm{p}=0.369$ ) in 5 year corrected visual acuity between eyes operated before and after 1 month of age.

\section{DISCUSSION}

In this series, the risk of glaucoma after congenital cataract surgery is similar to that reported previously ${ }^{12-17}$ with lensectomy carried out before 1 month of age being associated with a higher risk of glaucoma. ${ }^{14}{ }^{15} 22$ However, we did not find any evidence of a lower risk of glaucoma associated with lensectomy performed before 2 weeks of age. This is in contrast with the conclusion of the study of Watts et $a^{23}$ based on Classification and Regression Tree ${ }^{24}$ (CART) analysis. We felt that within the context of our study, CART offered no additional advantage over Kaplan-Meier survival analysis, which has been used in Johnson and Keech's study. ${ }^{25}$

The clinical presentation in our series can be broadly classified into two subtypes, the early angle closure glaucoma presenting within the first year after lensectomy and the late open angle glaucoma presenting after the first year. ${ }^{8}$ The angle closure subtype is usually associated with corneal oedema, pupil distortion, and drainage angle abnormalities in an inflamed eye. ${ }^{826}$ These signs can sometimes be detected with a handheld slit lamp. ${ }^{8}$ Open angle aphakic glaucoma usually presents as asymptomatic ocular hypertension up to years after uneventful lensectomy. ${ }^{3}$ There may be myopic shift and optic disc cupping if the diagnosis is delayed. None of the current tonometry technology, including Tonopen, Pulsair, and Perkins tonometers, is ideal for reliably measuring intraocular pressure in an uncooperative child. Frequently, examination under general anaesthetic is the only means of glaucoma evaluation in this age group. These factors make detection of open angle aphakic glaucoma in children between 1 and 5 years old challenging. Undetected glaucoma, rather than the natural history of the disorder, may account for a lower reported incidence in this age group. ${ }^{16} 25$

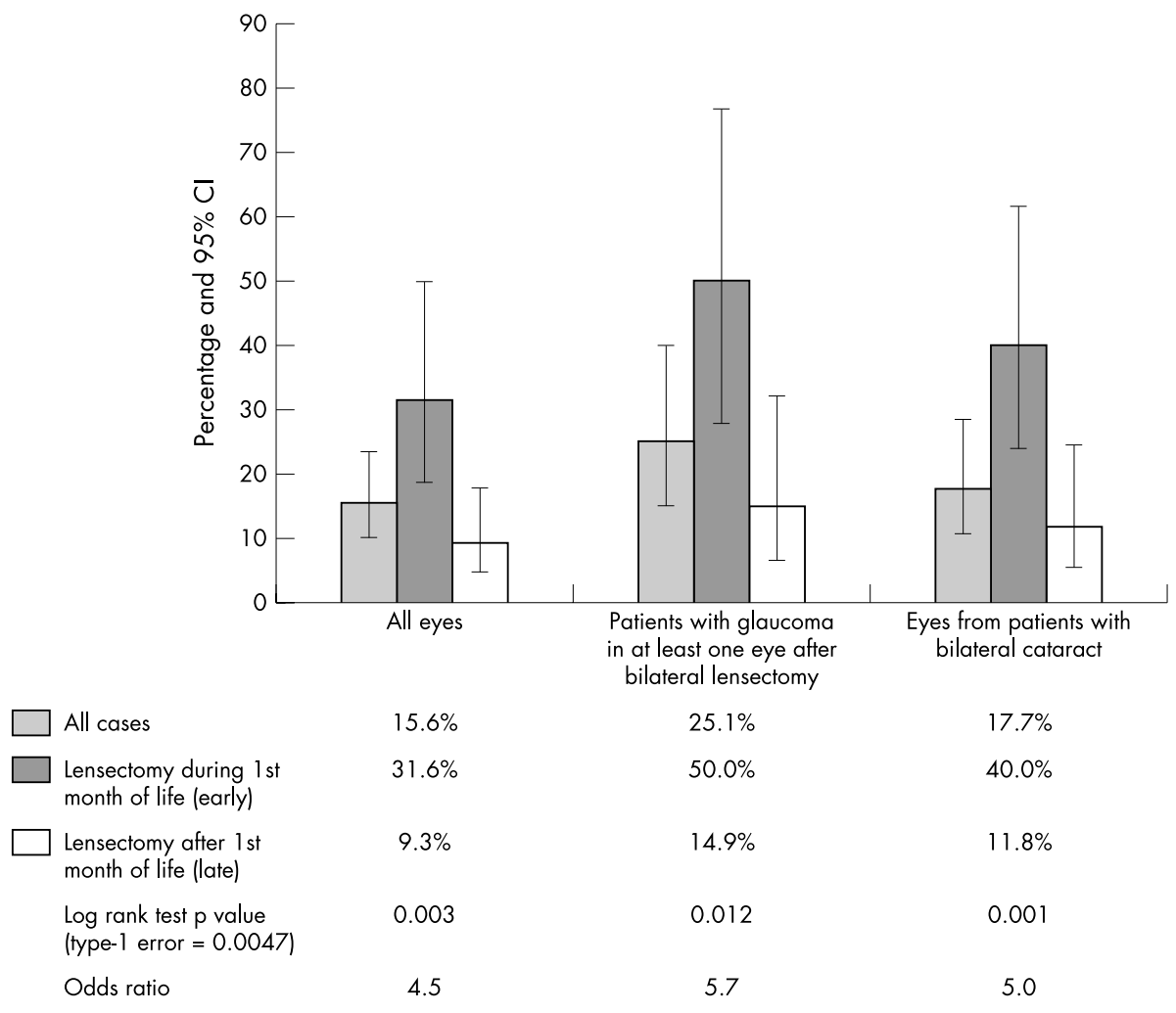

Figure 1 Five year risk of glaucoma after lensectomy based on eye count and patient count. The type 1 error for each of the 11 statistical hypotheses in this study was adjusted to 0.0047 rather than 0.05, based on Bonferroni correction. 


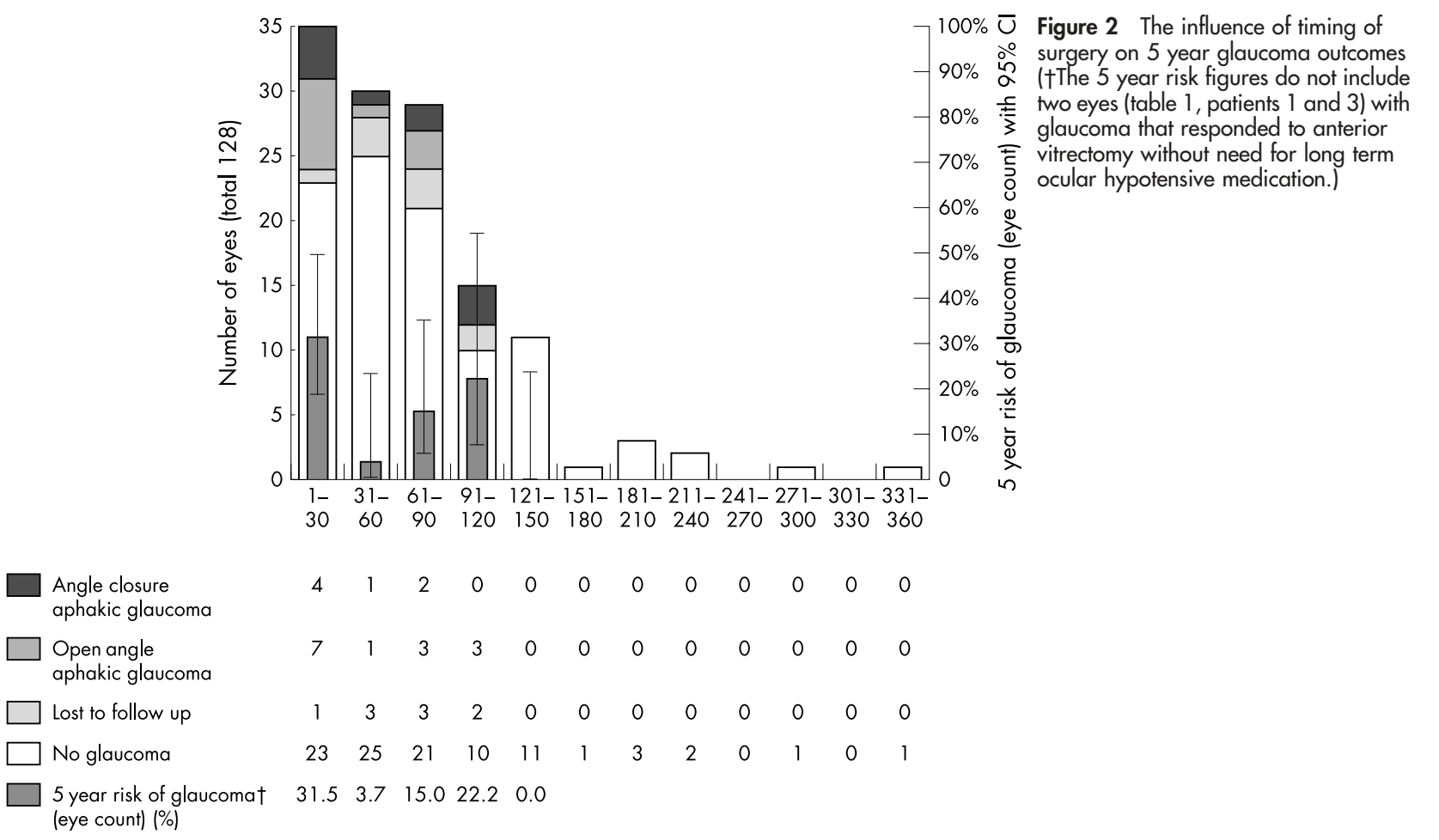

Simon et al $^{16}$ suggested a "guarantee time" of approximately $5 \frac{1}{2}$ years before glaucoma becomes apparent. In Johnson and Keech's series, ${ }^{25}$ there were virtually no new cases of glaucoma in year 2 and year 3 after surgery among eyes with infantile cataract, and no new cases of glaucoma in years 2, 3, and 4 among eyes with PHPV. Our results challenge the notion of a "guarantee time." The incidence of glaucoma remained statistically constant each year for the first 5 years after lensectomy.

The pathophysiology of aphakic glaucoma is still poorly understood and is likely to be multifactorial. In the case of angle closure aphakic glaucoma, both inflammatory and mechanical theories have been proposed. ${ }^{27}$ In very young eyes, the combination of difficult surgery, poor pupil dilation, ${ }^{6}$ and retained lens matter ${ }^{28}$ may contribute to a higher degree of postoperative inflammation and peripheral synechiae leading to early onset acute glaucoma. The lack of structural rigidity in young eyes may also lead to trabecular meshwork collapse and hence angle closure. ${ }^{9}$ With improvement of surgical techniques, including rigorous removal of lens matter, automated anterior vitrectomy, ${ }^{29}$ and closure of all wounds, this form of aphakic glaucoma is becoming relatively rare..$^{30}$

Open angle glaucoma is now the predominant form of postoperative aphakic glaucoma. Less is known about its underlying mechanisms. Postoperative inflammation is unlikely to be the direct cause in eyes presenting years after uneventful lensectomy. Walton reported acquired microperipheral anterior synechiae among eyes with late onset aphakic glaucoma. ${ }^{13}$ However, there is no proof that chronic subclinical inflammation and intermittent angle blockage may have any role. Early lensectomy on newborn infants has been reported to inhibit growth of the aphakic eye. ${ }^{31-33}$ Perhaps, early cataract surgery may also interfere with the maturation of the trabecular meshwork ultrastructure, ${ }^{834} 35$ leading to increased lifetime risk of open angle glaucoma. This could be mediated by factors like surgical barotrauma, early exposure of trabecular meshwork to vitreous, ${ }^{27}$ and to high dose corticosteroids.

Is there a familial genetic predisposition ${ }^{3}$ to cataract and early glaucoma? Infants are more likely to be operated earlier when they are detected and referred earlier, such as when
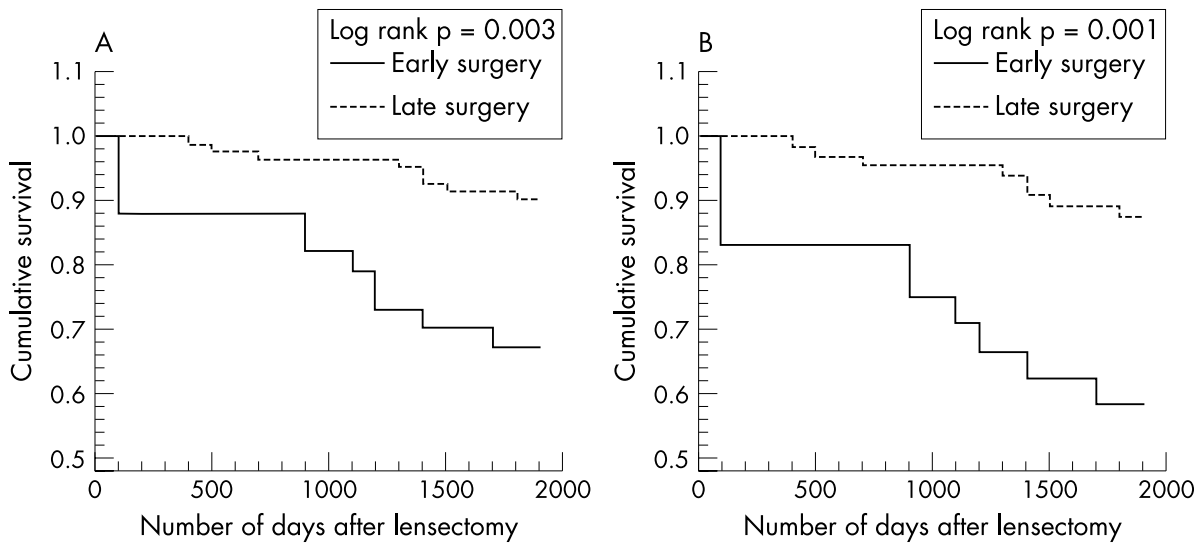

Figure 3 For all eyes (A) and for all eyes in patients undergoing bilateral lensectomy (B). Kaplan-Meier plots of glaucoma free survival after early and late lensectomy. 
Table 2 The incidence of glaucoma during the first 5 years

\begin{tabular}{|c|c|c|}
\hline \multirow[b]{2}{*}{ Year } & \multicolumn{2}{|l|}{ Incidence of aphakic glaucoma } \\
\hline & $\begin{array}{l}\text { Percentage of eyes after unilateral } \\
\text { or bilateral lensectomy and } 95 \% \mathrm{Cl}\end{array}$ & $\begin{array}{l}\text { Percentage of infants after bilateral } \\
\text { lensectomy and } 95 \% \mathrm{Cl}\end{array}$ \\
\hline $\begin{array}{l}1 \\
2 \\
3 \\
4 \\
5\end{array}$ & $\begin{array}{l}3.9 \% *(1.7 \text { to } 9.2) \\
1.7 \%(0.4 \text { to } 6.7) \\
2.6 \%(0.9 \text { to } 7.9) \\
6.4 \%(3.1 \text { to } 12.9) \\
1.96 \%(0.5 \text { to } 7.6)\end{array}$ & $\begin{array}{l}8.0 \%+(3.1 \text { to } 19.9) \\
4.6 \%(1.2 \text { to } 17.2) \\
4.9 \%(1.2 \text { to } 18.1) \\
10.3 \%(4.0 \text { to } 25.1) \\
0 \%(0 \text { to } 10.1)\end{array}$ \\
\hline Average incidence & $3.3 \%(2.1$ to 5.2$)$ & $5.6 \%$ (3.2 to 9.7$)$ \\
\hline $\begin{array}{l}\text { Log likelihood } I_{0}(d f=1) \\
\text { Log likelihood } I_{1}(d f=5) \\
\text { Deviance } D=-2\left(I_{0}-I_{1}\right) \\
\chi_{4}^{2} \text { test } p \text { value }\end{array}$ & $\begin{array}{l}-195.4 \\
-193.1 \\
4.6 \\
0.33\end{array}$ & $\begin{array}{l}-116.8 \\
-113.8 \\
5.9 \\
0.20\end{array}$ \\
\hline \multicolumn{3}{|c|}{$\begin{array}{l}\text { Model } I_{0} \text {, constant hazard model with constant incidence. The incidence remained statistically constant for the first } \\
5 \text { years. } \\
\text { Model } I_{1} \text {, piecewise constant hazard model with variable incidence. (*The incidence figures in year } 1 \text { do not } \\
\text { include two eyes (table } 1 \text {, patients } 1 \text { and } 3 \text { ) with glaucoma responded to anterior vitrectomy without need for long } \\
\text { term ocular hypotensive medication.) }\end{array}$} \\
\hline
\end{tabular}

there is a family history of cataract. In this series, seven out of 14 infants who underwent bilateral lensectomy before 1 month of age had a documented family history of congenital cataract as opposed to 21 out 36 infants who had bilateral surgery after 1 month of age. We did not find a statistically higher proportion $\left(\chi^{2}{ }_{1}\right.$ test $\left.p=0.9389\right)$ of infants who underwent early bilateral lensectomy with a familial history of congenital cataract. Thus, genetic predisposition alone does not account for the difference of glaucoma risk between infants operated during the first and second month of life.

Elston and Timms suggested a "period of grace" of the first 6 weeks of life, based on seven neonates who developed normal visual acuity after recovering from unilateral third nerve palsy, fourth nerve palsy, lid haematoma, or retinal haemorrhages by 6 weeks of age. ${ }^{21}$ Other authors suggested that congenital cataract surgery before 2 months of age produced the best visual outcomes. ${ }^{36}$

The "grace period" for bilateral cataracts is less well established in the literature, but is quite likely to be later than 6 weeks. Ellemberg et al reported subsequent contrast sensitivity deficits to high spatial frequencies, and to a lesser extend low temporal frequencies among children with bilateral dense cataract treated after 7 weeks of age. ${ }^{37}$

The key question emerging from our findings is "should we delay congenital cataract surgery until 4 weeks old?" In the case of bilateral congenital cataract, seven out of 14 infants operated before 1 month old eventually developed glaucoma in at least one eye and two of them (three eyes) had irreversible loss of vision from aggressive glaucoma. It may be prudent to consider delaying cataract surgery as late as possible before the end of the "grace period." In our study, we did not find any significant difference in final visual acuity with bilateral lensectomy carried out before and after 1 month of age.

In the case of unilateral cataracts, we did not have sufficient numbers to conduct separate risk factor analysis. Only two eyes out of 30 developed well controlled postoperative glaucoma. If unilateral and bilateral cataracts share similar pathophysiology, one can extrapolate that early surgery is also a risk factor for aphakic glaucoma in this subgroup. However, in this study we have not yet produced sufficient evidence to support this view. Because of the real risk of unilateral deprivation amblyopia, we are not ready to recommend delaying surgery for unilateral congenital cataract.

In conclusion, we have found that lensectomy for bilateral infantile cataract during the first month of life is associated with an increased risk of subsequent aphakic glaucoma compared with surgery performed later. The reason for this is not clear, but it may be prudent to consider delaying cataract surgery until the child is 4 weeks old. To settle the question whether we should delay surgery for unilateral cases, we are currently conducting a second study specifically on unilateral congenital cataracts.

As the incidence of glaucoma is similar for each year after surgery, long term glaucoma surveillance, starting immediately after operation, is mandatory. We recommend frequent anterior segment examination using a hand held slit lamp particularly during the first 4 months after surgery. Open angle glaucoma can be detected by regular intraocular pressure measurement, refraction, and optic disc examination. Screening for ocular hypertension is difficult in children less than 5 years old. Glaucoma evaluation under general

Table 3 The incidence of glaucoma with early versus late surgery

\begin{tabular}{|c|c|c|}
\hline & \multirow{2}{*}{$\begin{array}{l}\text { Unilateral and bilateral lensectomy } \\
\text { Percentage of eyes with glaucoma }\end{array}$} & \multirow{2}{*}{$\frac{\text { Bilateral lensectomy }}{\text { Percentage of infants with glaucoma }}$} \\
\hline & & \\
\hline \multicolumn{3}{|c|}{ Early and late surgery combined } \\
\hline 5 Year risk & $15.6 \%(95 \% \mathrm{Cl} 10.2$ to 23.4$)$ & $25.1 \%(95 \% \mathrm{Cl} 15.1$ to 40.0$)$ \\
\hline Average Incidence & $3.3 \%(95 \% \mathrm{Cl} 2.1$ to 5.2$)$ & $5.6 \%(95 \% \mathrm{Cl} 3.2$ to 9.7$)$ \\
\hline \multicolumn{3}{|c|}{ Early surgery before 1 month old } \\
\hline 5 Year risk & $31.6 \%(95 \% \mathrm{Cl} 18.9$ to 49.7$)$ & $50 \%(95 \% \mathrm{Cl} 27.8$ to 77.1$)$ \\
\hline Average incidence & $7.3 \%(95 \% \mathrm{Cl} 4.1$ to 12.8$)$ & $12.9 \%(95 \% \mathrm{Cl} 6.3$ to 25.6$)$ \\
\hline \multicolumn{3}{|c|}{ Late surgery after 1 month old } \\
\hline 5 Year risk & $9.3 \%(95 \% \mathrm{Cl} 4.7$ to 17.7$)$ & $14.9 \%(95 \% \mathrm{Cl} 6.5$ to 32.1$)$ \\
\hline Average incidence & $1.9 \%(95 \% \mathrm{Cl} 1.0$ to 3.8$)$ & $3.2 \%(95 \% \mathrm{Cl} 1.3$ to 7.5$)$ \\
\hline
\end{tabular}


Table 4 The influence of timing of lensectomy on the 5 year corrected visual acuity

\begin{tabular}{|c|c|c|c|c|c|}
\hline \multirow[b]{2}{*}{ Lensectomy timing } & \multicolumn{5}{|l|}{ Number of eyes } \\
\hline & $\log M A R \quad 0.5$ or befter & $\log M A R 0.6-1.00$ & $\begin{array}{l}\text { Worse than } \\
\text { logMAR } 1.00\end{array}$ & Missing records & Total \\
\hline \multicolumn{6}{|c|}{ Unilateral lensectomy subgroup } \\
\hline $0-28$ days old & 4 & 3 & 3 & 0 & 10 \\
\hline$>28$ days old & 5 & 4 & 8 & 3 & 20 \\
\hline \multirow[t]{2}{*}{ Total } & & 7 & 11 & 3 & 30 \\
\hline & \multicolumn{5}{|c|}{ Kolmogorov-Smirnov test, $D_{N=27}=0.247, p$ (two tailed) $=0.587$} \\
\hline \multicolumn{6}{|c|}{ Bilateral lensectomy subgroup } \\
\hline $0-28$ days old & 14 & 4 & 6 & 1 & 25 \\
\hline$>28$ days old & 27 & 28 & 6 & 12 & 73 \\
\hline \multirow[t]{2}{*}{ Total } & 41 & 32 & 12 & 13 & 98 \\
\hline & \multicolumn{5}{|c|}{ Kolmogorov-Smirnov test, $D_{N=85}=0.197, p$ (two tailed) $=0.369$} \\
\hline
\end{tabular}

anaesthetic should be considered if the child is not able to cooperate to allow adequate examination.

\section{ACKNOWLEDGEMENTS}

We thank Dr Mohamed Abdolell of Cancer Care Ontario for his invaluable biostatistics advice.

\section{Authors' affiliations}

M Vishwanath, R Cheong-Leen, D Taylor, The Visual Science Unit, Institute of Child Health, London, UK

I Russell-Eggitt, The Eye Department, Great Ormond Street Hospital, London, UK

J Rahi, The Paediatric Epidemiology and Biostatistics Unit, Institute of Child Health, London, UK

\section{REFERENCES}

1 Barkhash SA, Pikalova LD, Grechko AS. [Secondary glaucoma after extraction of congenital cataract in children]. Oftalmol Zh 1975;30:204-6.

2 Francois J. Glaucoma and uveitis after congenital cataract surgery. Ann Ophthalmol 1971;3:131-5.

3 Phelps CD, Arafat NI. Open-angle glaucoma following surgery for congenital cataracts. Arch Ophthalmol 1977:95:1985-7.

4 Pressman SH, Crouch ER Jr. Pediatric aphakic glaucoma. Ann Ophthalmol 1983;15:568-73.

5 Kornacki B, Goryszewska-Macioch H, Szreter M, et al. [Twelve year observation of the eyes after lensectomy]. Klin Oczna 1994:96:216-18.

6 Mills MD, Robb RM. Glaucoma following childhood cataract surgery. J Pediatr Ophthalmol Strabismus 1994;31:355-60, discussion 361.

7 Ariturk N, Oge I, Mohajery F, et al. Secondary glaucoma after congenital cataract surgery. Int Ophthalmol 1998;22:175-80.

8 Russell-Eggitt I, Zamiri P. Review of aphakic glaucoma after surgery for congenital cataract. J Cataract Refract Surg 1997;23(Suppl 1):664-8.

9 Papadopoulos M, Khaw PT. Meeting the challenge of glaucoma after paediatric cataract surgery. Eye 2003;17:1-2.

10 Asrani SG, Wilensky JT. Glaucoma after congenital cataract surgery. Ophthalmology 1995;102:863-7

11 Lee AF, Lee SM, Chou JC, et al. Glaucoma following congenital cataract surgery. Zhonghua Yi Xue Za Zhi (Taipei) 1998;61:65-70.

12 Robb RM, Petersen RA. Outcome of treatment for bilateral congenital cataracts. Ophthalmic Surg 1992;23:650-6.

13 Walton DS. Pediatric aphakic glaucoma: a study of 65 patients. Trans Am Ophthalmol Soc 1995;93:403-13, discussion 413-20.

14 Magnusson G, Abrahamsson M, Sjostrand J. Glaucoma following congenital cataract surgery: an 18-year longitudinal follow-up. Acta Ophthalmol Scand 2000;78:65-70.

15 Keech RV, Tongue AC, Scott WE. Complications after surgery for congenital and infantile cataracts. Am J Ophthalmol 1989;108:136-41.

16 Simon JW, Mehta N, Simmons ST, et al. Glaucoma after pediatric lensectomy/vitrectomy. Ophthalmology 1991;98:670-4.
17 Miyahara S, Amino K, Tanihara H. Glaucoma secondary to pars plana lensectomy for congenital cataract. Graefes Arch Clin Exp Ophthalmol 2002;240:176-9

18 Egbert JE, Wright MM, Dahlhauser KF, et al. A prospective study of ocular hypertension and glaucoma after pediatric cataract surgery. Ophthalmology 1995; 102:1098-101

19 Chrousos GA, Parks MM, O'Neill JF. Incidence of chronic glaucoma, retinal detachment and secondary membrane surgery in pediatric aphakic patients. Ophthalmology 1984;91:1238-41.

20 Rahi JS, Dezateux C. National cross sectional study of detection of congenital and infantile cataract in the United Kingdom: role of childhood screening and surveillance. The British Congenital Cataract Interest Group. BMJ 1999:318:362-5.

21 Elston JS, Timms C. Clinical evidence for the onset of the sensitive period in infancy. Br J Ophthalmol 1992;76:327-8.

22 Lundvall A, Kugelberg U. Outcome after treatment of congenital bilateral cataract. Acta Ophthalmol Scand 2002;80:593-7.

23 Watts $\mathbf{P}$, Abdolell $M$, Levin AV. Complications in infants undergoing surgery for congenital cataract in the first 12 weeks of life: is early surgery better? J AAPOS 2003;7:81-5

24 Breiman L, Friedman $\mathrm{JH}$, Olshen RA, et al. Classification and regression trees, 1st ed. Belmont, CA: Wadsworth, 1984

25 Johnson CP, Keech RV. Prevalence of glaucoma after surgery for PHPV and infantile cataracts. J Pediatr Ophthalmol Strabismus 1996;33:14-17.

26 Wang VM, Demer JL, Rosenbaum A, et al. Diagnosing glaucoma in pediatric aphakia. Optometry 2002;73:704-10.

27 Asrani S, Freedman S, Hasselblad V, et al. Does primary intraocular lens implantation prevent "aphakic" glaucoma in children? J AAPOS 2000;4:33-9

28 Kugelberg U, Lundvall A, Lundgren B, et al. After-cataract and secondary glaucoma in the aphakic infant rabbit. J Cataract Refract Surg 2000;26:1398-402.

29 Vasavada A, Desai J. Primary posterior capsulorhexis with and without anterior vitrectomy in congenital cataracts. J Cataract Refract Surg 1997;23(Suppl 1):645-51.

30 Parks MM, Johnson DA, Reed GW. Long-term visual results and complications in children with aphakia. A function of cataract type. Ophthalmology 1993; 100:826-40, discussion 840-1

31 Kugelberg U, Zetterstrom C, Lundgren B, et al. Eye growth in the aphakic newborn rabbit. J Cataract Refract Surg 1996;22:337-41.

32 Wilson JR, Fernandes A, Chandler CV, et al. Abnormal development of the axial length of aphakic monkey eyes. Invest Ophthalmol Vis Sci 1987;28:2096-9.

33 Griener ED, Dahan E, Lambert SR. Effect of age at time of cataract surgery on subsequent axial length growth in infant eyes. J Cataract Refract Surg 1999;25:1209-13

34 McMenamin PG. A morphological study of the inner surface of the anterior chamber angle in pre and postnatal human eyes. Curr Eye Res 1989;8:727-39.

35 Reme C, d'Epinay SL. Periods of development of the normal human chamber angle. Doc Ophthalmol 1981;51:241-68.

36 Birch EE, Stager DR. Prevalence of good visual acuity following surgery for congenital unilateral cataract. Arch Ophthalmol 1988;106:40-3.

37 Ellemberg D, Lewis TL, Maurer D, et al. Spatial and temporal vision in patients treated for bilateral congenital cataracts. Vis Res 1999;39:3480-9. 